Case Report

\title{
A RARE CASE OF CHONDROM A OF CARTILAGINOUS NASAL SEPTUM
}

\author{
Shrinath D. Kamath P. ${ }^{1}$, Kishore Shetty ${ }^{2}$, Anusha Shetty ${ }^{3}$, \\ Michelle Mathias ${ }^{4} \&$ Natashya Rent ${ }^{5}$ \\ ${ }^{1}$ Associate Professor, ${ }^{2,4}$ Professor, ${ }^{3}$ Resident, ${ }^{5}$ Assistant Professor \\ Department of E N T, ${ }^{4}$ Department of Pathology, K. S. Hegde Medical Academy, \\ Nitte University, Mangalore, Karnataka, INDIA.
}

Correspondence:

Shrinath D. Kamath P.

Associate Professor, Department of E.N.T. K. S. Hegde Medical Academy, Nitte University Deralakatte, M angalore 575018, Karnataka, India. E-mail : drshrinath.kamath@gmail.com

\begin{abstract}
:
Chondroma is a benign tumor of cartilaginous origin. Nasal septal chondromas are rare and almost always arise from the bony septum. Considering the very rare occurrence of chondroma from anterior part of the septum, we report a case of Chondroma of the nasal septal cartilage in an adult female, who presented with progressive unilateral nasal obstruction. CT scan showed the minimally enhancing lesion from the anterior septum confined to the left nasal cavity. Excision of the mass was done endoscopically. Histopathological examination of the specimen was suggestive of chondroma.
\end{abstract}

Keywords: Chondroma; Nasal septum; Endoscopic excision.

\section{Introduction:}

A chondroma is a benign cartilaginous neoplasm which makes up for second largest bone neoplasms. Cartilaginous tumors of head and neck are rare. The sites of predilection in the

head and neck region include ethmoid sinus (50\%), maxilla (18\%), nasal septum (17\%), hard palate and nasopharynx including sphenoid sinus (6\% each), and alar cartilage (3\%). ${ }^{1}$ Nasal Chondromas are very rare; since 1842 only about 150 cases of chondroma involving the nose have been reported ${ }^{2}$ and only 19 cases of chondromas arising from the nasal septum are reported ${ }^{3}$. They present with nasal obstruction, bleeding and headache. Treatment of choice is surgical excision. Histopathological examination of the specimen is necessary for diagnosis. Considering the

\begin{tabular}{|c|}
\hline Access this article online \\
\hline Quick Response Code \\
\hline \\
\hline
\end{tabular}

\section{Case Report:}

A 42 year old lady presented with progressive left sided nasal obstruction over a period of one year with intermittent frontal headache. There was no history of nasal discharge or nasal bleeding. Anterior Rhinoscopy showed a reddish fleshy mass filling the left nasal cavity which obscured the view of inferior and middle turbinates. The mass was firm in consistency and did not bleed on touch. There was no cervical lymphadenopathy. Contrast CT scan of nasal cavity and paranasal sinuses revealed a minimally enhancing homogenous soft tissue mass in the left nasal cavity, arising from the nasal septum, filling the anterior part of nasal cavity with thinning of the left lateral nasal wall (Fig 1). Posteriorly the bony septum was intact (Fig 2). No intratumoral calcification, local tissue destruction or cervical lymphadenopathy was seen. Endoscopic excision of nasal mass was done under general anesthesia. Anterior nasal pack was kept in the left nasal cavity, which was removed after 24 hours. Postoperative period was uneventful. The histopathology examination of the specimen showed nodules of mature cartilaginous tissue with lacunae containing benign chondrocytes, fibrocollagenous tissue and blood vessels. Overlying areas 
showed pseudostratified columnar epithelium. Foci of bony trabeculae were seen (Fig 3). Histopathological feature was suggestive of chondroma. The patient is under regular follow up and is asymptomatic for last 8 months, with no evidence of recurrence on follow up diagnostic nasal endoscopy.

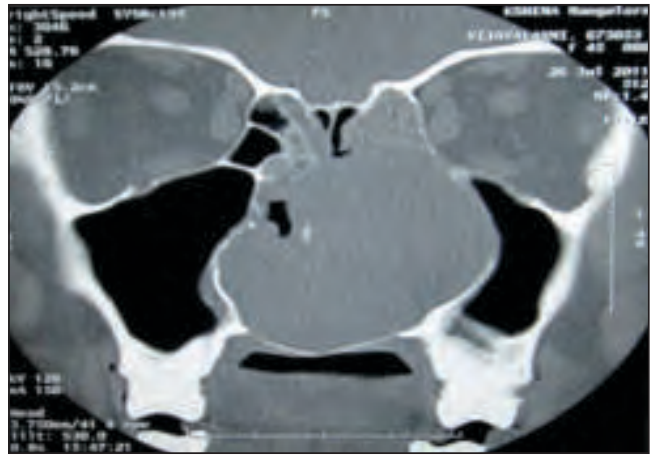

Fig 1 : C T scan of Nose and PNS, Coronal View : Homogenous opacity arising from the septum occupying the left nasal cavity. Left lateral wall isthinned out.

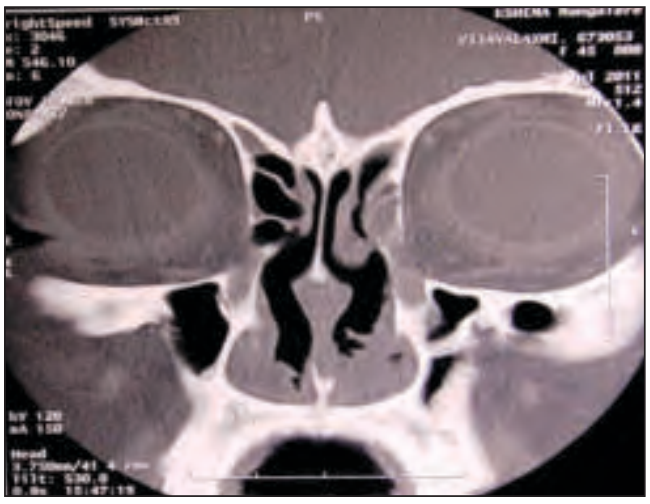

Fig 2 : CTscan of Nose and PNS, Coronal View : Posterior septum is intact

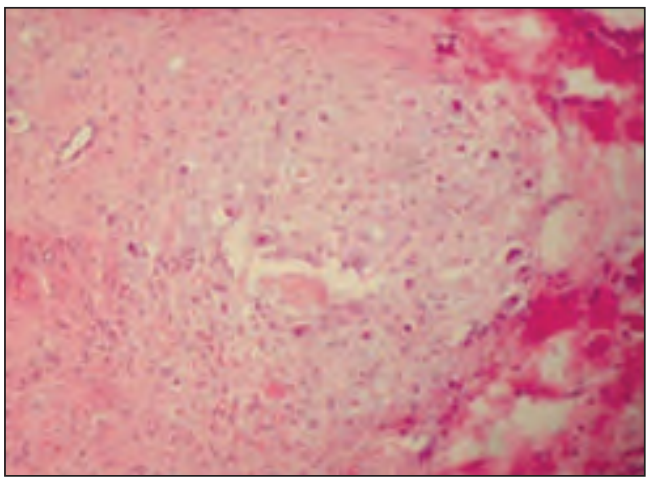

Fig 3 : Histopathology : Stroma showing nodules of mature cartilageous tissue with lacunae containing benign chondrocytes, fibrocollagenous tissue and blood vessels. Foci of bony trabeculae is also seen.

\section{Discussion:}

Chondroma of the nasal cavity is a rare neoplasm. Approximately $60 \%$ of tumors occur in patients less than 50 years old ${ }^{4}$. In the facial skeleton, chondroma generally seen in adolescence and early adulthood ${ }^{5}$. There is no gender predilection. The most common reported sites in the facial skeleton are the ethmoid sinuses and the nasal cavity excluding the nasal septum $(50 \%)^{2}$.The most accepted theory of origin of nasal chondroma is "cell rest theory" which explains the chondrogenesisfrom paranasal sinuses, turbinates, hard palate or posterior part of septum.

The symptoms of nasal chondromas depend on the site, size, and rate of growth of the tumor. Chondroma of the nasal cavity are characterized by slow growth, with the symptoms of nasal obstruction and epistaxis?. Extension into the orbits may cause proptosis, epiphora, diplopia, and even blindness. Patients in whom the maxilla is involved may complain of toothaches and ill fitting dentures. Imaging is needed to evaluate the bone and soft-tissue characteristics of the tumor and to assess its full extent. CT scan of the Nose and Paranasal sinuses with contrast helps in assessing the extent of the tumor. In general, nasal chondromas are not radio-opaque ${ }^{7}$. Chondromas are usually well circumscribed and appear fairly homogeneous on a computed tomography $\operatorname{scan}^{4}$. The diagnosis of nasal chondroma is based on combination of clinical, radiologic and pathologic findings. When diagnosis is doubtful, M RI may be undertaken where a chondroma exhibits higher signal intensity on $T 2 W 1^{8}$.

On macroscopic examination, chondromas are smooth, firm, and lobulated tumors with a gritty "ripe pear feel." On microscopy, cartilage cells are consistently small and contain pale, vacuolated cytoplasm and small, round, darkstained nuclei. Some fields may show binucleate cartilage cells, indicating a process of amitotic division, but most are monocellular and mononucleate ${ }^{2}$.

The differential diagnosis of nasal cavity mass lesions include both inflammatory and neoplastic conditions. Nasal polyps, fungal infections, rhinosporidiosis, tuberculosis, wegener's granulomatosis and lethal midline 
granuloma present as nasal cavity soft-tissue mass lesions with or without bone destruction ${ }^{4}$.

M ost authors advocate surgical excision as the mainstay of treatment for nasal chondromas. For a large tumor arising from the septum lateral rhinotomy approach is preferred. This approach is also preferred in cases with paranasal sinus involvement ${ }^{2}$. For small lesions limited to the nasal cavity, endoscopic approach providea a safe and effective approach without complications. In general, cartilaginous tumors are radioresistant. Radiotherapy is of little value for histopathologically benign tumors, but it may be offered

\section{References:}

1. M Zillur Rahman, A K M Shaifuddin, Aliya Shahnaz, P.K Ghosh.Chondroma of the Nasal Septum-A Case Report and Review of Literature. Pakistan Journal of Otolaryngology 2012; 28 : 97-99

2. Sreedharan S, Kamath MP, Hegde MC, Sundar S, Lobo FD, Raju PK. Chondroma of the nasal bone: a case report. Ear Nose Throat J. 2006 Jan;85(1):44-6.

3. Rivas Lacarte MP, Perello Scherdel E, Novell V (1996) : Solitarychondroma of the nasal septum. Anales Otorrinolaringologicos Iberoamericanos 23(4):431-4.

4. Patanakar T, Armao D, Mukherji SK. American Journal of Roentgenology(2000). 174:4;11665. Faccini JM, Williams JL. Nasal chondroma. J Larnyngol Otol 1973;87:811-16.

6. Ringertz N. Pathology of malignant tumors arising in the nasal and paranasal cavities and maxilla. Acta Otolaryngologica supplement(1938):27:1;405

7. Kilby D, Ambegaokar AG. The nasal chondroma. 2 case reports and a survey of the literature. J Larnyngol Otol 1977;91:415-26.

8. Ruark DS, Schlehaider VK, Shah JP (2002). Chondrosarcomas of the head and neck. World Journal of head and neck Surgery 16(2) 10101016. for the treatment of primary and recurrent malignant cartilaginous tumors ${ }^{2}$. Recurrence of anteriorly lying septal chondroma after radical excision is unknown. This may be due to paucity of clinical data on this rare condition or due to a comparatively lesser complex anatomy anteriorly where the potential for involving vital structures is less and the tumour can be easily accessed completely for a radical excision. Long-term follow-up of a benign chondroma is necessary because of the possibility that malignant transformation will occur. The prognosis is good and recurrence is uncommon with appropriate treatment. 